\title{
Reward Network Immediate Early Gene Expression in Mood Disorders
}

\author{
Claire E. Manning, Elizabeth S. Williams and Alfred J. Robison* \\ Department of Physiology, Michigan State University, East Lansing, MI, USA
}

Over the past three decades, it has become clear that aberrant function of the network of interconnected brain regions responsible for reward processing and motivated behavior underlies a variety of mood disorders, including depression and anxiety. It is also clear that stress-induced changes in reward network activity underlying both normal and pathological behavior also cause changes in gene expression. Here, we attempt to define the reward circuitry and explore the known and potential contributions of activity-dependent changes in gene expression within this circuitry to stress-induced changes in behavior related to mood disorders, and contrast some of these effects with those induced by exposure to drugs of abuse. We focus on a series of immediate early genes regulated by stress within this circuitry and their connections, both well-explored and relatively novel, to circuit function and subsequent reward-related behaviors. We conclude that IEGs play a crucial role in stress-dependent remodeling of reward circuitry, and that they may serve as inroads to the molecular, cellular, and circuit-level mechanisms of mood disorder etiology and treatment.

\section{OPEN ACCESS}

Edited by:

Amelia Gallitano,

University of Arizona, USA

Reviewed by:

Clive R. Bramham,

University of Bergen, Norway

David Dietz,

University at Buffalo, USA

*Correspondence:

Alfred J. Robison robiso45@msu.edu

Received: 19 December 2016 Accepted: 11 April 2017 Published: 28 April 2017

Citation:

Manning CE, Williams ES and Robison AJ (2017) Reward Network Immediate Early Gene Expression in Mood Disorders.

Front. Behav. Neurosci. 11:77. doi: 10.3389/fnbeh.2017.00077
Keywords: depression, reward system, immediate early gene (IEG), FosB/ $\Delta$ FosB, CREB, accumbens, hippocampus, mood disorders

\section{INTRODUCTION}

Neurocircuitry has evolved to reward behaviors that contribute to evolutionary fitness with feelings of pleasure, motivating individual organisms to value, and repeat actions that increase the likelihood of propagating their genetic material. These may include having sex, eating certain foods, caring for offspring, or engaging in social activity. However, the modern human environment, replete with abundant resources and access to pleasurable stimuli, may allow increased reward processing to induce maladaptive pursuits, such as overeating or addiction to drugs or sex (Berridge and Kringelbach, 2015). Conversely, deficiency in reward processing contributes to the anhedonic symptoms of mood disorders like depression (Nestler, 2015a; Luking et al., 2016), and current treatment and research in mood disorders focuses on the circuitry underlying reward and the mechanisms that may contribute to defective reward processing.

Rewarding behaviors become favored because they are reinforced. This process requires that they: (1) give rise to positive emotions (pleasure), (2) induce learning, and (3) produce additional consummatory behavior (i.e., eating, copulating, interacting, etc.). Thus, the reward circuitry must integrate information from brain structures that drive feelings of pleasure, formation and storage of memories, and decision-making and behavioral output. It has become increasingly clear over the last two decades that changes in gene transcription within this reward circuitry contribute to the development of mood disorders (Nestler, 2015a). These disease-related changes can involve mechanisms as diverse as histone and DNA modification, non-coding RNA expression, and 
transcription factor induction and activity (Dalton et al., 2014; Geaghan and Cairns, 2015; Nestler, 2015a). The expression of many transcription factors involved in these processes is tightly regulated by neuronal activity, and such transcription factors belong to a class of molecules termed immediate early genes (IEGs). These IEGs represent a particularly attractive mechanism for diseases involving anhedonia, as reward circuit neuronal activity is altered in many models of depression (Russo and Nestler, 2013; Lammel et al., 2014), and thus the expression of many IEGs is dysregulated in the same models (Reul, 2014; Nestler, 2015a). Therefore, to fully unravel the etiology of human mood disorders, it is critical that we uncover the regulation of IEGs in the reward circuitry under both basal and disease conditions. This review will cover progress in identifying the regulation and downstream targets of IEGs within the brain regions comprising the reward circuitry, and the current evidence linking reward circuitry IEGs to stress responses and mood disorders.

\section{THE CORTICO-BASAL GANGLIA REWARD NETWORK}

The central feature of the reward circuitry is the release of dopamine (DA) from the ventral tegmental area (VTA) neurons into limbic brain regions that control prediction, perception, and processing of rewarding stimuli. VTA DA neurons have major projections to the prefrontal cortex (PFC; the mesocortical pathway) and to the nucleus accumbens (NAc; the mesolimbic pathway), but also project to hippocampus, amygdala, and several other forebrain regions. Mesocortical DA is thought to be involved in emotional responses and control of cognition (Nestler et al., 2015), while mesolimbic DA is traditionally linked to reward and motivated behaviors. Mesolimbic DA release activates dopamine receptors (DRs) on NAc medium spiny neurons (MSNs), GABAergic cells comprised of two largely separate populations that express predominantly either D1 or D2 DRs (Surmeier et al., 2007; Lobo, 2009). D1 MSNs comprise the "direct" pathway, which ultimately increases thalamocortical drive, while D2 MSNs make up the "indirect" pathway, which results in reduced thalamocortical drive. Because D1 DRs increase responsiveness to glutamatergic excitation while D2 DRs decrease this glutamate excitability, VTA DA release facilitates the direct pathway while putting a brake on the indirect pathway, with the combined effect of increased cortical drive.

NAc MSNs receive glutamatergic inputs from several cortical and limbic structures, including medial and lateral divisions of the PFC, ventral hippocampus (vHPC), basolateral amygdala (BLA), and medial thalamus (Sesack and Grace, 2010; Floresco, 2015). PFC inputs onto NAc regulate goal-directed behaviors, such as seeking and consuming substances/activities associated with reward, including food, sex, drugs, and social interactions (Kalivas et al., 2005; Gruber et al., 2009), providing the "executive control" required for planning and performing actions to obtain rewards. vHPC inputs onto NAc presumably provide information regarding affective valence of locations in space and previous experience generated from emotional learning.
This applies to both positive and negative emotional states, i.e., reward- and aversion-based learning, including contextdependent fear conditioning, feeding behavior, and responses to drugs of abuse (Vezina et al., 1989; Fanselow, 2000; Kanoski and Grill, 2017). While general BLA activity and BLA projections to many other brain regions regulate fear-related learning and behavior, glutamatergic inputs from BLA onto NAc MSNs increases reward seeking and supports positive reinforcement (Ambroggi et al., 2008; Stuber et al., 2011; Janak and Tye, 2015).

Many of these NAc glutamatergic input regions also project to each other, and NAc MSNs send and receive GABAergic projections to and from the VTA as well. This results in a complex cortico-basal ganglia reward network (Sesack and Grace, 2010; Floresco, 2015), a simplified version of which is presented here (Figure 1A). The ultimate function of this network is to regulate and integrate cortical/limbic glutamatergic signals representing executive control, memory, and emotion with dopaminergic reward processing to control the thalamocortical outputs that drive behavior. Critically, many of the regions involved in this circuit undergo long-term changes in gene expression, and cell function, often as a result of stress exposure, that may drive mood-related disorders, and these changes result, in part, from aberrant expression and function of IEGs. This is particularly evident in stress-induced changes in the structure of reward network neurons.

Chronic social defeat stress, a rodent model of depression, causes an increase in dendritic spine density in NAc MSNs (Figure 1B). MSN dendritic spines are the structural correlate of glutamatergic inputs, and the number and shape of spines represent the number and strength of those individual inputs. The increased spine density observed in the NAc after chronic social defeat stress (CSDS) is due primarily to an increase in the number of stubby spines, which are immature, and there is no change in mature mushroom-shaped spines (Christoffel et al., 2011). Stubby spines are associated with smaller postsynaptic densities (PSDs) and weaker responses to glutamate, but the increase in their density after stress may represent an increase in glutamatergic signaling to the NAc, and it is indeed accompanied by an increase in the number (but not amplitude) of miniature excitatory postsynaptic potentials (mEPSPs; Christoffel et al., 2011). In addition to stress paradigms such as CSDS, the administration of psychostimulants such as cocaine also increases dendritic spine density, mainly due to an increase in the number of thin spines (Robinson and Kolb, 1999; Russo et al., 2010), a shape also considered immature. However, in contrast to stress, stimulant drug administration increases dendritic spine complexity in NAc MSNs, with many spines showing branching with multiple heads (Robinson and Kolb, 1999; Figure 1B). This increase in complexity may represent a reorganization and increase in synaptic signaling, indicating a change in circuit function after drug experience. Many gene products may be involved in the regulation of dendritic spines in the stressed and drug-exposed states, including several of the IEGs discussed below (e.g., $\triangle$ FosB, CREB; Maze et al., 2010; Russo et al., 2010). A better understanding of the links between IEG expression and structural and functional plasticity of the reward network is critical to 


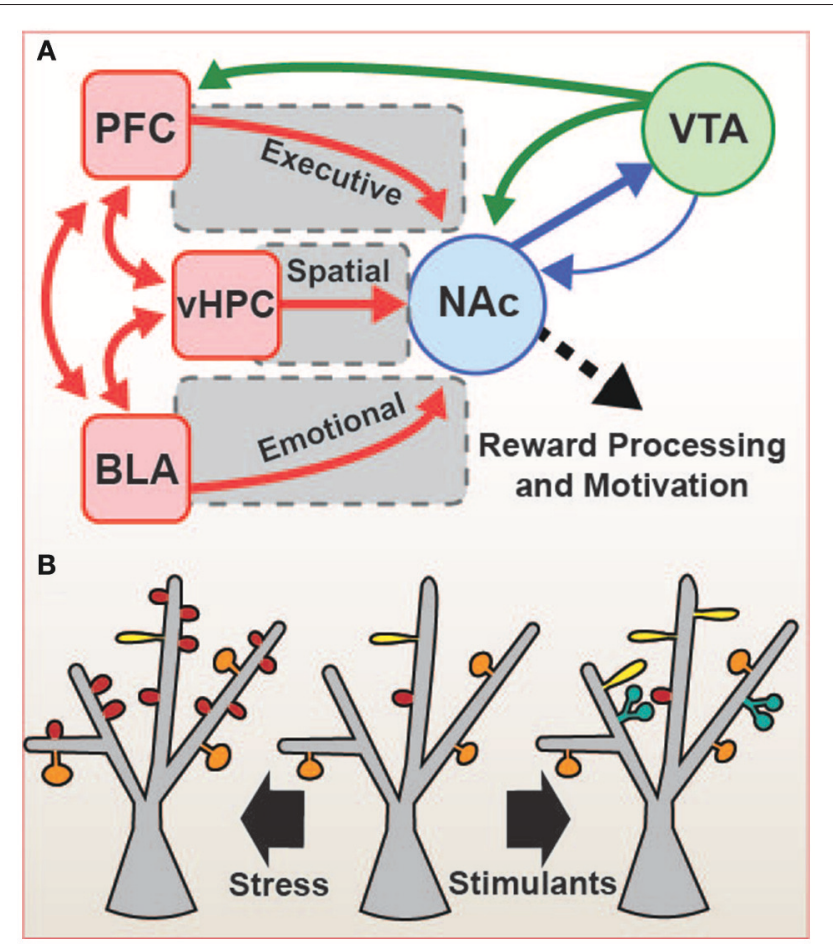

FIGURE 1 | Cortico-basal ganglia reward network. (A) The nucleus accumbens (NAc) integrates glutamatergic inputs (red) which regulate spatial (ventral hippocampus, vHPC), emotional (basolateral amygdala, BLA), and executive (prefrontal cortex, PFC) behaviors, and these inputs are modulated by dopamine (green) from the ventral tegmental area (VTA). BLA, vHPC, and PFC are also interconnected, allowing for further integration of the circuitry. The sum of these inputs results in reward-related learning and decision-making. Stress can cause alteration in the expression of IEGs throughout these brain regions, altering the function and structure these connections, and this may result in pathological changes in reward perception and motivation, including the anhedonia or despair common to many mood disorders. (B) Strength and number of glutamatergic connections correlate with changes in the shape and number of dendritic spines in NAc. In chronic social defeat stress (CSDS, left), an increase in the number of stubby (red) spines is observed, while in stimulant drug administration (e.g., cocaine and amphetamines, right), the numbers of thin (yellow), and branched (blue) spines are increased. These structural changes may be mediated by IEGs, and may represent a key factor in the circuit-level changes observed in the depressed and addicted disease states.

the development of our understanding of mood and addiction pathologies.

\section{CAMP RESPONSE ELEMENT-BINDING PROTEIN (CREB)}

CREB is a transcription factor that binds to the canonical cAMP response element (CRE) in DNA in response to activation of signaling pathways involving cAMP, $\mathrm{Ca}^{2+} /$ calmodulin, or various growth factors and/or cytokines. CREB activation of target gene transcription (Figure 2) is controlled by phosphorylation at serine 133 by protein kinase A (PKA, downstream of cAMP), $\mathrm{Ca}^{2+} /$ calmodulin-dependent protein kinase IV (CaMKIV, downstream of $\mathrm{Ca}^{2+}$ ), and/or MAP kinase

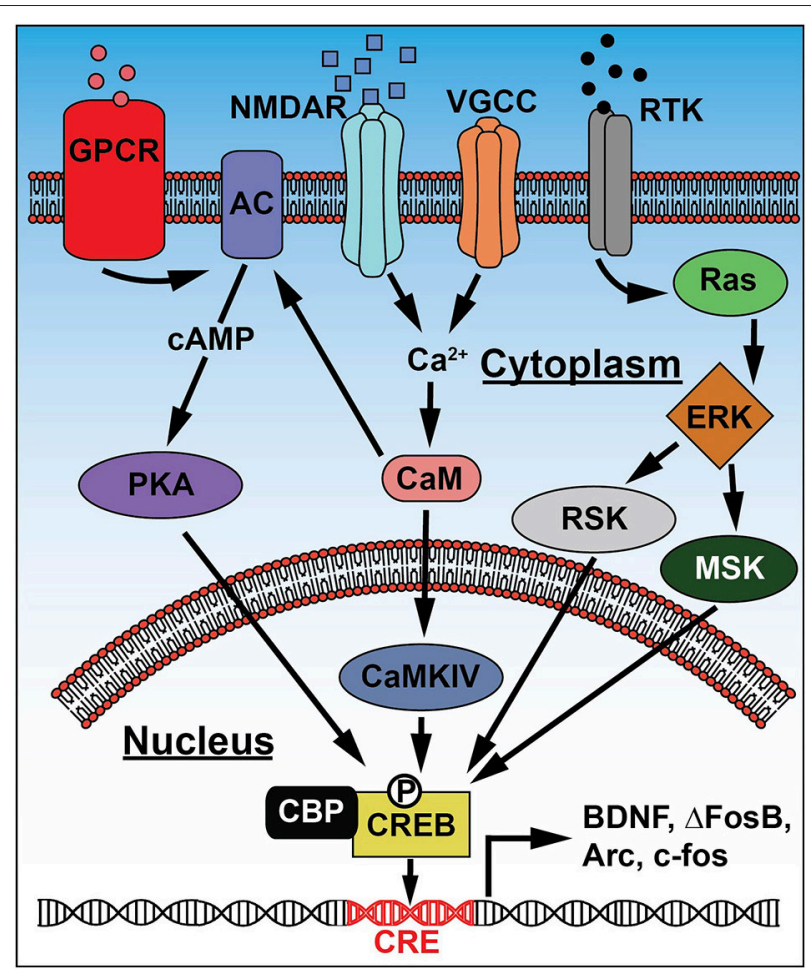

FIGURE 2 | Signaling pathways leading to CREB activation. Extracellular signals and changes in membrane potential activate receptors and channels including: G-protein coupled receptors (GPCR), NMDA-type glutamate receptors (NMDAR), voltage gated $\mathrm{Ca}^{2+}$ channels (VGCC), and receptor tyrosine kinases (RTK). These generate increases in second-messenger (cAMP and $\mathrm{Ca}^{2+}$ ) or MAPK signaling that converge on kinase activation: protein kinase $\mathrm{A}(\mathrm{PKA}), \mathrm{Ca}^{2+} /$ calmodulin-dependent protein kinase IV (CaMKIV), extracellular signal-regulated kinase (ERK), ribosomal S6 kinase (RSK), and mitogen and stress-activated kinase (MSK). Subsequent phosphorylation at Ser133 activates CREB and promotes interaction with CREB-binding protein (CBP), causing CREB to bind cAMP response elements (CRE) in the promoter regions of target genes and increase expression of proteins that regulate neuronal function, like BDNF and IEGs such as Arc, $\triangle F$ FosB, and c-fos.

signaling (downstream of growth factors and cytokines; Kida and Serita, 2014). Ser133 phosphorylation promotes interaction with CREB-binding protein (CBP), a critical step for transcriptional activation (Chrivia et al., 1993). The earliest and most extensive studies of CREB's role in neuronal function centered on its control of gene transcription underlying long-term potentiation of synapses and memory formation. CREB is critical for memory and synaptic plasticity in the invertebrate sea slug Aplysia (Dash et al., 1990; Kandel, 2012) and fruit fly (Yin et al., 1994), and long-term memory is impaired in CREB loss-of-function mice, but enhanced in CREB gain-of-function mice, primarily due to its role in the hippocampus (summarized in Kida and Serita, 2014).

CREB is stimulated in NAc by exposure to various stressors, and its activation in NAc has been linked to a variety of emotional responses, with the general consensus being that chronic activation of CREB in NAc leads to anhedonia while inhibition of CREB function in NAc promotes reward (Barrot et al., 2002; Carlezon et al., 2005). Moreover, reduced CREB 
activity in NAc appears to have antidepressant-like effects in multiple stress models (Pliakas et al., 2001; Conti et al., 2002; Newton et al., 2002; Covington et al., 2011), suggesting that stress-induced CREB activation in NAc may contribute to the etiology of depression. However, the opposite appears true with regard to anxiety-like behaviors, as increased NAc CREB activity appears anxiolytic while inhibition of NAc CREB promotes anxiety (Barrot et al., 2002, 2005; Wallace et al., 2009), indicating that manipulation of NAc CREB activity may not be a simple therapeutic inroad to treatment of mood disorders.

In contrast to its function in NAc, CREB activation in hippocampus produces an antidepressant effect (Chen et al., 2001), and it is indeed induced in the hippocampus by a variety of antidepressant treatments (Nibuya et al., 1996; Thome et al., 2000). One of the many identified target genes of CREB is brain-derived neurotrophic factor (BDNF), and BDNF is also induced in hippocampus by antidepressants (Nibuya et al., 1995) and it is a key transducer of antidepressant effects (Björkholm and Monteggia, 2016). This CREB-BDNF pathway has been postulated to induce hippocampal neurogenesis as a crucial step in antidepressant action (Duman, 2004; Carlezon et al., 2005). It therefore follows that dysfunction of CREB in hippocampus may underlie both depression and some of the cognitive dysfunction linked to chronic stress that are often comorbid with mood disorders (Bortolato et al., 2014). It is also critical to note that CREB regulates the expression of many other IEGs linked to stress responses and depression, including FosB, c-fos, and Arc (see below), and so may act as a master regulator of the activity-dependent transcriptional response to stress throughout the reward circuitry.

\section{AP-1 PROTEINS-c-fos, FosB/ $\Delta$ FosB, JUN}

Activator protein 1 (AP1) is a complex composed of heterodimers between Fos family proteins, Jun family proteins, Jun dimerization proteins, and/or activating transcription factor (ATF) proteins that, when assembled, act as potent and specific regulators of gene transcription. A typical AP1 complex consists of Fos-Jun heterodimers that utilize leucine zippers present in both proteins for dimerization and a basic region that interacts with DNA. The Fos family of transcription factors is comprised of c-fos, FosB (and its splice variants, $\Delta$ FosB and $\Delta 2 \Delta$ FosB), Fra1, and Fra2, all of which are induced by neuronal activity. $c$-fos is transiently and robustly induced, with a half-life ranging from minutes up to a couple hours (Sheng and Greenberg, 1990; Kovács, 1998; Ferrara et al., 2003), and is hypothesized to target a wide variety of genes associated with cell differentiation, cell and synapse development, synaptic plasticity, and learning (Alberini, 2009; West and Greenberg, 2011). Its clear connection to cellular activity has led to its use as a marker of brain region activation in a range of behavioral and physiological conditions, however conclusive evidence for c-fos-specific gene targets has not yet been provided, and its direct role in neuronal function remains obscure. It is induced throughout the reward circuitry by virtually all emotionally salient stimuli (Kovács, 1998; Cruz et al., 2015; Nestler, 2015b), but its functional role in mood disorders and antidepressant responses is not well-understood.
FosB is encoded by the Fos $B$ gene and shares many characteristics with c-fos: FosB has low basal expression and is transiently and robustly induced by neuronal activity (Nestler et al., 1999), with a similar short half-life in cells to that of c-fos (Dobrazanski et al., 1991; Ferrara et al., 2003; Ulery et al., 2006). Splice variation of FosB gene transcripts produces a premature stop codon resulting in the truncated $\Delta$ FosB protein, which lacks two c-terminal degron domains lending it increased stability (Carle et al., 2007). Most other IEGs have a half-life of a few hours, while $\triangle \mathrm{FosB}$ has an unusually long-half life, up to 7 days in vivo (Hope et al., 1994; Andersson et al., 2003; UleryReynolds et al., 2009), making it a marker of chronic neuronal activity. $\triangle$ FosB is induced throughout the reward circuitry by chronic stress (Perrotti et al., 2004) and chronic antidepressant exposure (Vialou et al., 2015), and like CREB (which is essential for $\triangle$ FosB induction, Vialou et al., 2012), the behavioral effects of its expression differ by brain region. In the NAc, $\triangle \mathrm{FosB}$ is induced by chronic social defeat stress, and its induction is greater in animals resilient to the behavioral effects of stress than in those susceptible to the depression-like phenotype (Vialou et al., 2010a). Moreover, $\triangle$ FosB induction in NAc promotes resilience to chronic stress and is necessary for the antidepressant effects of SSRIs like fluoxetine (Vialou et al., 2010a), apparently through modulation of AMPA receptor subunit expression and epigenetic regulation of CaMKII $\alpha$ expression (Vialou et al., 2010a; Robison et al., 2014). Its induction by stress in resilient mice appears specific to D1-type MSNs in NAc, while a lower level of induction is seen in D2-type MSNs of susceptible mice (Lobo et al., 2013). Indeed, the specific overexpression of $\Delta$ FosB in D1 MSNs appears to have antidepressant effects (Vialou et al., 2010a; Muschamp et al., 2012; Donahue et al., 2014), and it alters the structure of glutamatergic synapses on these specific neurons. $\Delta$ FosB promotes the expression of immature thin and stubby dendritic spines, and a concomitant increase in silent synapses, in D1 but not D2 MSNs (Grueter et al., 2013), suggesting that it selectively alters glutamatergic inputs onto NAc direct pathway output neurons, directly modulating reward processing.

In the medial PFC, $\triangle$ FosB is selectively induced in mice susceptible to chronic social defeat stress (Vialou et al., 2014). Further, in direct opposition to its effects in NAc D1 MSNs, $\triangle \mathrm{FosB}$ inhibition in $\mathrm{mPFC}$ neurons promotes resilience to chronic stress, while $\Delta \mathrm{FosB}$ overexpression drives susceptibility, at least in part through induction of the cholecystokininB receptor (Vialou et al., 2014). The effect appears to be mediated by $\triangle$ FosB expression in $\mathrm{mPFC}$ neurons that project to NAc, emphasizing the critical nature of activity-dependent gene expression within the circuitry of reward. We recently reported that $\Delta$ FosB expression in hippocampus is critical for multiple forms of learning (Eagle et al., 2015), but the role of hippocampal $\triangle F o s B$ in stress responses and mood disorders, both locally and in projections to NAc or PFC, remains unknown.

\section{SERUM RESPONSE FACTOR (SRF)}

SRF is a transcription factor that binds specifically to the serum response element found in the promoters of many other IEGs and a number of cardiac-specific genes (Knöll and Nordheim, 2009). In the adult brain, SRF is required for activity-induced gene 
expression and synaptic plasticity but not for neuronal survival (Ramanan et al., 2005). Through its mediation of the expression and function of cytoskeletal-associated proteins, SRF seems to be instrumental in converting synaptic activity into plasticityassociated structural changes in neuronal circuits (Knöll and Nordheim, 2009), making it a potential player in the activitydependent gene expression underlying stress-induced changes in reward circuitry. Indeed, SRF is induced in the NAc of resilient mice after chronic social defeat stress, and it binds to the Fos $B$ promoter and increases transcription of the gene (Vialou et al., 2010b). The subsequent SRF-dependent stress induction of $\Delta$ FosB is critical for the resilient phenotype, and, unlike cocainedependent induction of $\triangle \mathrm{FosB}$, appears independent of CREB actions at the FosB promoter (Vialou et al., 2010b, 2012).

\section{EARLY GROWTH RESPONSE PROTEIN-1 (Egr-1)}

Egr-1, also known as zinc finger protein 268, is an activitydependent neuronal transcription factor that binds DNA via three distinct zinc finger domains. It appears to play a role in neuronal plasticity (Knapska and Kaczmarek, 2004), perhaps through its regulation of the expression of synaptobrevin II (Petersohn and Thiel, 1996). Egr-1 is induced in hippocampus by acute stress, like forced swim in rats, through activation of a complex epigenetic mechanism stemming from hippocampal glucocorticoid receptor (GR) activation (summarized in Reul, 2014). MAPK signaling downstream of GRs drives MSK1 and Elk-1 activity, a pathway also upstream of CREB and cfos induction. This favors Ser10 phosphorylation and Lys14 acetylation of histone 3 at the Erg-1 gene promoter, leading to relaxed chromatin compaction, changes in DNA methylation, and Erg-1 expression (Gutièrrez-Mecinas et al., 2011; Saunderson et al., 2016). This effect lasts at least days in the brain, and may be responsible for subsequent altered responses to forced swim, perhaps underlying long-term stress-induced despair, a hallmark of mood disorders. Indeed, Egr-1 expression is reduced in both hippocampus and PFC by social isolation (Ieraci et al., 2016), indicating that it may contribute to long-term changes in mood due to prolonged stress. In the future, it will be critical to determine whether the effects of Egr-1 expression in hippocampus occur due to alteration of hippocampal projections to or from other reward circuitry components, such as NAc.

Egr-3, which colocalizes with Egr-1 and is also induced in an activity-dependent manner, has recently been implicated in multiple mood disorders. Egr-3's many targets include Arc (Li et al., 2005), discussed below, as well as NMDA and GABA receptor subunits (Roberts et al., 2005; Kim et al., 2012), suggesting that it may contribute to excitatory/inhibitory balance in reward circuitry. Initial studies using SNPs in the Egr-3 gene found a potential association with child bipolar disorder (Gallitano et al., 2012). A more recent study used large-scale microarray data and found that Erg-3 may play a critical role in dysregulation of PFC transcriptional networks in patients with bipolar depression (Pfaffenseller et al., 2016). Moreover, rodent studies suggest that Egr-3 may underlie some of the effects of clozapine in treating both psychosis and bipolar symptoms (Gallitano-Mendel et al., 2008; Williams et al., 2012), suggesting that further study of Egr-3 may yield critical insights into the etiology of mood disorders.

\section{NPAS4}

Neuronal PAS domain protein 4, or NPAS4, is an activitydependent transcription factor expressed exclusively in neurons. It is necessary for normal development of inhibitory interneurons as well as neuronal plasticity in response to experience (Lin et al., 2008; Ploski et al., 2011; Ramamoorthi et al., 2011; Sim et al., 2013). Since NPAS4 is induced in both excitatory and inhibitory neurons and initiates distinct cascades in each cell type (Spiegel et al., 2014), it is thought to regulate excitatory and inhibitory balance within circuits (Bloodgood et al., 2013). Identified downstream targets of NPAS4 include brain-derived neurotrophic factor (BDNF) in excitatory neurons, and FERM and PDZ domain-containing protein 3 (Frmpd3) in inhibitory neurons (Spiegel et al., 2014).

In HPC, NPAS4 induction by both synaptic potentiation and depression protocols requires MAPK and PI3K pathways (Coba et al., 2008), suggesting a link to activation of other IEGs, like CREB. Stress directly mediates NPAS4 activation, as agonist bound glucocorticoid receptor binds to the NPAS4 promoter to downregulate its expression during acute stress (Furukawa-Hibi et al., 2012). After chronic stress, NPAS4 mRNA is significantly decreased in the hippocampus of juvenile mice, and these NPAS4-deficient juveniles developed cognitive deficits in adulthood (Ibi et al., 2008; Yun et al., 2010; Coutellier et al., 2015). These long-term changes may arise through epigenetic regulation, as the NPAS4 promoter has several CpG islands, and stress increases methylation at these sites (Furukawa-Hibi et al., 2015). Several animal strains, including SERT knockout rats and the Flinders Sensitive Line, have shown correlations between low NPAS4 expression, depressive-like behaviors, and antidepressant resistance (Guidotti et al., 2012; Bigio et al., 2016). Much of this work has been done in HPC, and further studies are needed to characterize the role of NPAS4 in NAc and other reward circuitry areas in the context of the same depression models. Moreover, NPAS4 is upregulated in NAc after exposure to drugs of abuse (Guo et al., 2012), but is role in drug responses or behaviors underlying addiction remains unknown.

\section{ACTIVITY-REGULATED CYTOSKELETON-ASSOCIATED PROTEIN (Arc)}

Arc is a flexible, modular, multidomain protein that interacts with many partners (Myrum et al., 2015; Zhang et al., 2015). Through these interactions, Arc serves to maintain the phosphorylation of the actin depolymerization factor cofilin, preserving its inactive form, and thus favors the polymerization of actin (Messaoudi et al., 2007). In this manner, Arc promotes the induction of thin, immature dendritic spines, a function shared with $\triangle F$ FosB (see above). Importantly, Arc is also localized 
to the postsynaptic density where it plays a critical role in internalization of AMPA receptors (Chowdhury et al., 2006) and promotes formation of immature dendritic spines (Peebles et al., 2010) and long-term depression (LTD; Bramham et al., 2010).

Recent evidence suggests that Arc expression and function may be tied to multiple aspects of depression. In a variety of rat and mouse paradigms, Arc is consistently induced throughout the cortex and hippocampus by acute stress, but may be up- or down-regulated by chronic stressors depending on the paradigm (Elizalde et al., 2010; Molteni et al., 2010; Boulle et al., 2014). In addition, the vast majority of studies suggest that chronic antidepressant treatment induces Arc expression throughout rodent cortex and hippocampus, and stress-induced Arc expression in specific brain regions appears to predict the subsequent effects of stress on cognitive function (summarized in $\mathrm{Li}$ et al., 2015). Thus, it seems possible that stress- or antidepressantinduced Arc may be critical for remodeling of reward circuitry synapses, perhaps in glutamatergic inputs to NAc or connections between other cortical and basal-ganglia regions, but further study will be required to determine the exact contribution of Arc expression to stress responses and mood disorders.

\section{HOMER1A}

Homer1 proteins act primarily as scaffolds mediating the interactions and locations of other neuronal proteins, including metabotropic glutamate receptors (e.g., mGluR1 and mGluR5), $\mathrm{IP}_{3}$ receptors, Shank, and others. The short splice variant of Homer1, Homerla, is induced by neuronal activity and acts as a dominant negative to block interactions of the long, constitutively active splice variants (Homer1b and Homer1c) with their normal ligands via competition for EVH1 binding sites. For example, Homerla has been shown to uncouple mGluR receptors from downstream signaling (Tu et al., 1998) as well as cause a decrease in the size and density of dendritic spines (Sala et al., 2003) via inhibition of Shank targeting to synapses. The Homer 1 gene is implicated in the pathogenesis of major depression through genome-wide association as well as neuroimaging studies (Rietschel et al., 2010). In a repeated forced swim mouse model of depression, Homerla is reduced in cortex, and this is reversed by antidepressant exposure (Sun et al., 2011). Interestingly, Homer1b and 1c are induced in HPC by social defeat stress (Wagner et al., 2015), and increasing their levels in proportion to Homerla may act as a mechanism of resilience. This is because overexpression of Homerla in mouse HPC promotes susceptibility to social defeat stress, with overexpressing animals showing increased behavioral despair and less active coping behavior (Wagner et al., 2015). In the accumbens, Homerla is induced by antipsychotics that act at dopamine receptors (reviewed in Iasevoli et al., 2009), but any role of Homerla in accumbens-mediated behavioral responses to stress and drugs of abuse remains to be uncovered.

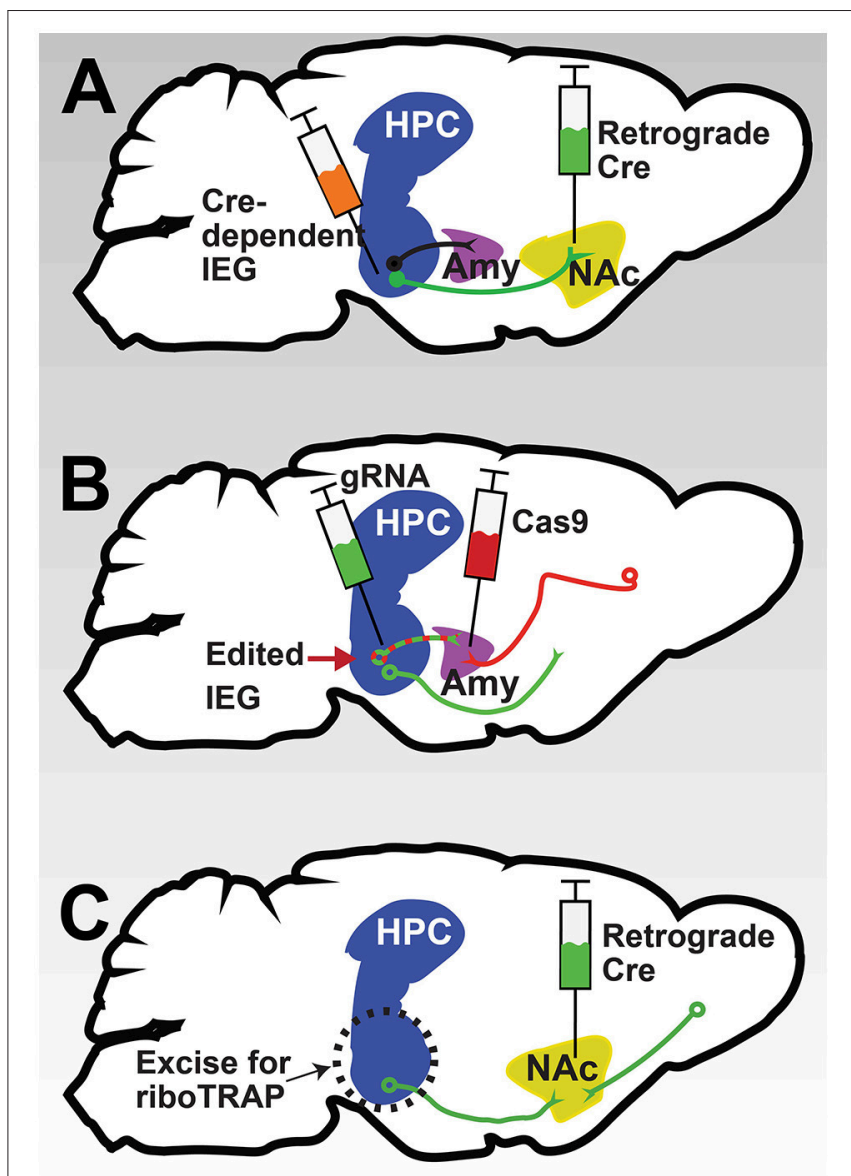

FIGURE 3 | Potential methods for circuit-specific interrogation of IEG function. (A) Schematic depicting the combination of a retrograde Cre virus (green) injected into a target region like NAc with a local virus expressing an IEG in a Cre-dependent manner injected into a projecting region like ventral HPC. Such a strategy would result in overexpression of the IEG only in HPC neurons projecting to NAc. (B) Schematic of a converse strategy: the combination of a retrograde virus expressing Cas9 (red) in a target region like amygdala (Amy) with a local virus expressing a guide RNA targeting an IEG (green) in a projecting region like ventral HPC could be used to silence an IEG in a specific circuit. (C) Schematic of a strategy for uncovering circuit-specific gene expression. Using a retrograde Cre virus in a target region to induce expression of GFP-tagged ribosomes in the projection region allows the use of TRAP to determine gene expression changes in the circuit. By combining this approach with mice floxed for a specific IEG, circuit-specific IEG transcriptional targets could be revealed.

\section{OUTSTANDING QUESTIONS AND FUTURE DIRECTIONS}

Despite accumulating evidence of IEG induction within reward circuitry in rodent models and patients with mood disorders, we still don't fully understand the contribution of IEGs to reward circuitry function and pathological behavior. A critical next step is to target IEGs in specific neural circuits. Such an approach has been difficult using classical techniques, but recent advances in cell labeling and cell- and circuit-specific manipulation provide exciting avenues to address some critical outstanding questions. 


\section{Are There Distinct Roles for IEGs in Specific Neuronal Subtypes?}

Do IEGs perform the same functions in all neuronal cell types? Because some IEGs are induced more sparsely compared to others (e.g., NPAS4), the relevance of IEG expression to mood disorders may be tied to their induction in specific cell populations. Transgenic mouse lines allowing selective overexpression or knockout of IEGs in neurons that produce specific neurotransmitters (i.e., DAT-Cre or GAD-Cre) or express specific receptors (i.e., D1-Cre or D2-Cre) will be a critical tool in future studies. Moreover, coupling these lines with Credependent viral vectors will address the role of IEGs in individual neuronal subtypes with both spatial and temporal specificity.

\section{What Is the Role of IEGs in Specific Brain Circuits?}

Although IEGs may be activated in many brain regions in response to stress or drugs, their relevance in circuits underlying addiction and depression behaviors is not fully understood. To assess the contribution of activated IEG suites within mesolimbic and cortical circuitry to cell function and animal behaviors, novel retrograde viral vector approaches will be critical. For instance, by combining a retrograde virus expressing Cre injected into a target region such as NAc with a locally expressing virus overexpressing an IEG of interest in a Cre-dependent manner injected into ventral HPC, one could measure the effects of the IEG on the function of HPC neurons specifically projecting to NAc, as well as subsequent behavior of the animal (Figure 3A). Alternatively, by combining retrograde expression of the Cas 9 enzyme with a local expression of guide RNA, CRISPR-mediated editing of an IEG could be used to determine its circuit specific role (Figure 3B), an approach currently being piloted by our group and others. Of course, these techniques could be combined with transgenic Cre driver lines described above to allow cell-type and circuit-specific manipulation of IEGs, critical steps for our understanding of their role in the pathophysiology of psychiatric disease.

\section{What Are the Gene Targets of IEGs in Specific Cell Types and Circuits?}

Although it is critical to understand the roles of IEGs in specific cell types, neuronal ensembles, and specific circuits, many IEGs make unlikely pharmacological targets for treatment of psychiatric disease, as they often play critical roles in non-disease-related brain regions and other tissues. However, uncovering the gene targets of IEG transcription factors, like Fos family proteins or NPAS4, may reveal critical mediators of pathophysiology that are more amenable to pharmacological manipulation. New advances in gene expression profiling, like translating ribosomal affinity purification (TRAP; Heiman et al., 2014), are sufficiently flexible and robust to be applied to Credependent cell- and circuit-specific approaches described above (Lobo, 2009; McCullough et al., 2016), and primed for use in Credependent ensemble-specific approaches (Sakurai et al., 2016). Utilizing Cre-dependent reporter mouse lines expressing GFPtagged ribosomes in combination with retrograde Cre viruses will allow circuit-specific TRAP profiling of gene expression (Figure 3C). Combining such an approach with mice floxed for a specific IEG will then allow assessment of the contribution of that IEG to circuit-specific gene expression in the context of stress or drugs. We predict that such techniques will uncover novel gene products underlying mood or substance use disorders that could be pharmacologically accessible targets for novel treatments.

\section{CONCLUSIONS}

It is clear that exposure to stressful events in life increases risk for mood disorders, and the many preclinical and fewer postmortem studies summarized here suggest that this may arise in part from stress-induced remodeling of reward circuitry driven by IEG expression. For some of these IEGs, like CREB, Homerla, and $\Delta$ FosB, evidence abounds for their roles in stress responses, multiple aspects of mood disorders, drug addiction, and even antidepressant treatment, and the challenge now lies in integrating their functions across the brain regions and cell types involved and determining their downstream targets in order to uncover potential novel drug targets. For other IEGs, such as Egr-1, NPAS4, and Arc, their induction by stress makes them molecules of interest in mood disorder research, but causal connections to depression-related behaviors have not yet been uncovered, and continued study of their role in reward circuitry function is needed. In all cases, it has become clear that stressdependent remodeling of the reward circuitry, and particularly of glutamatergic inputs to NAc, is a critical component in the development of depression- and addiction-related phenotypes, and that IEGs play a crucial role in this process and may provide a pathway to the molecular, cellular, and circuit-level mechanisms of mood disorder etiology and treatment.

\section{AUTHOR CONTRIBUTIONS}

$\mathrm{CM}, \mathrm{EW}$, and AR researched, wrote, and edited the manuscript.

\section{FUNDING}

This work was funded by awards to AR from the National Institute of Mental Health (1R01MH111604-01) and the Whitehall Foundation (2013-08-43).

\section{REFERENCES}

Alberini, C. M. (2009). Transcription factors in long-term memory and synaptic plasticity. Physiol. Rev. 89, 121-145. doi: 10.1152/physrev.00017.2008

Ambroggi, F., Ishikawa, A., Fields, H. L., and Nicola, S. M. (2008). Basolateral amygdala neurons facilitate reward-seeking behavior by exciting nucleus accumbens neurons. Neuron 59, 648-661. doi: 10.1016/j.neuron.2008. 07.004 
Andersson, M., Westin, J. E., and Cenci, M. A. (2003). Time course of striatal $\triangle$ FosB-like immunoreactivity and prodynorphin mRNA levels after discontinuation of chronic dopaminomimetic treatment. Eur. J. Neurosci. 17, 661-666. doi: 10.1046/j.1460-9568.2003.02469.x

Barrot, M., Olivier, J. D., Perrotti, L. I., DiLeone, R. J., Berton, O., Eisch, A. J., et al. (2002). CREB activity in the nucleus accumbens shell controls gating of behavioral responses to emotional stimuli. Proc. Natl. Acad. Sci. U.S.A. 99, 11435-11440. doi: 10.1073/pnas.172091899

Barrot, M., Wallace, D. L., Bolanos, C. A., Graham, D. L., Perrotti, L. I., Neve, R. L., et al. (2005). Regulation of anxiety and initiation of sexual behavior by CREB in the nucleus accumbens. Proc. Natl. Acad. Sci. U.S.A. 102, 8357-8362. doi: 10.1073/pnas.0500587102

Berridge, K. C., and Kringelbach, M. L. (2015). Pleasure systems in the brain. Neuron 86, 646-664. doi: 10.1016/j.neuron.2015.02.018

Bigio, B., Mathe, A. A., Sousa, V. C., Zelli, D., Svenningsson, P., McEwen, B. S., et al. (2016). Epigenetics and energetics in ventral hippocampus mediate rapid antidepressant action: Implications for treatment resistance. Proc. Natl. Acad. Sci. U.S.A. 113, 7906-7911. doi: 10.1073/pnas.1603111113

Björkholm, C., and Monteggia, L. M. (2016). BDNF - a key transducer of antidepressant effects. Neuropharmacology 102, 72-79. doi: 10.1016/j.neuropharm.2015.10.034

Bloodgood, B. L., Sharma, N., Browne, H. A., Trepman, A. Z., and Greenberg, M. E. (2013). The activity-dependent transcription factor NPAS4 regulates domain-specific inhibition. Nature 503, 121-125. doi: 10.1038/nature12743

Bortolato, B., Carvalho, A. F., and McIntyre, R. S. (2014). Cognitive dysfunction in major depressive disorder: a state-of-the-art clinical review. CNS Neurol. Disord. Drug Targets 13, 1804-1818. doi: 10.2174/18715273136661411302 03823

Boulle, F., Massart, R., Stragier, E., Paizanis, E., Zaidan, L., Marday, S., et al. (2014). Hippocampal and behavioral dysfunctions in a mouse model of environmental stress: normalization by agomelatine. Transl. Psychiatry 4, e485. doi: $10.1038 /$ tp. 2014.125

Bramham, C. R., Alme, M. N., Bittins, M., Kuipers, S. D., Nair, R. R., Pai, B., et al. (2010). The Arc of synaptic memory. Exp. Brain Res. 200, 125-140. doi: 10.1007/s00221-009-1959-2

Carle, T. L., Ohnishi, Y. N., Ohnishi, Y. H., Alibhai, I. N., Wilkinson, M. B., Kumar, A., et al. (2007). Proteasome-dependent and -independent mechanisms for FosB destabilization: identification of FosB degron domains and implications for $\Delta$ FosB stability. Eur. J. Neurosci. 25, 3009-3019. doi: 10.1111/j.1460-9568.2007.05575.x

Carlezon, W. A. Jr., Duman, R. S., and Nestler, E. J. (2005). The many faces of CREB. Trends Neurosci. 28, 436-445. doi: 10.1016/j.tins.2005.06.005

Chen, A. C., Shirayama, Y., Shin, K. H., Neve, R. L., and Duman, R. S. (2001). Expression of the cAMP response element binding protein (CREB) in hippocampus produces an antidepressant effect. Biol. Psychiatry 49, 753-762. doi: 10.1016/S0006-3223(00)01114-8

Chowdhury, S., Shepherd, J. D., Okuno, H., Lyford, G., Petralia, R. S., Plath, N., et al. (2006). Arc/Arg3.1 interacts with the endocytic machinery to regulate AMPA receptor trafficking. Neuron 52, 445-459. doi: 10.1016/j.neuron.2006.08.033

Christoffel, D. J., Golden, S. A., Dumitriu, D., Robison, A. J., Janssen, W. G., Ahn, H. F., et al. (2011). IkappaB kinase regulates social defeat stress-induced synaptic and behavioral plasticity. J. Neurosci. 31, 314-321. doi: 10.1523/JNEUROSCI.4763-10.2011

Chrivia, J. C., Kwok, R. P., Lamb, N., Hagiwara, M., Montminy, M. R., and Goodman, R. H. (1993). Phosphorylated CREB binds specifically to the nuclear protein CBP. Nature 365, 855-859. doi: 10.1038/365855a0

Coba, M. P., Valor, L. M., Kopanitsa, M. V., Afinowi, N. O., and Grant, S. G. (2008). Kinase networks integrate profiles of N-methyl-D-aspartate receptormediated gene expression in hippocampus. J. Biol. Chem. 283, 34101-34107. doi: 10.1074/jbc.M804951200

Conti, A. C., Cryan, J. F., Dalvi, A., Lucki, I., and Blendy, J. A. (2002). cAMP response element-binding protein is essential for the upregulation of brainderived neurotrophic factor transcription, but not the behavioral or endocrine responses to antidepressant drugs. J. Neurosci. 22, 3262-3268.

Coutellier, L., Gilbert, V., and Shepard, R. (2015). Npas4 deficiency increases vulnerability to juvenile stress in mice. Behav. Brain Res. 295, 17-25. doi: $10.1016 /$ j.bbr.2015.04.027
Covington, H. E. III, Maze, I., Sun, H., Bomze, H. M., DeMaio, K. D., Wu, E. Y., et al. (2011). A role for repressive histone methylation in cocaine-induced vulnerability to stress. Neuron 71, 656-670. doi: 10.1016/j.neuron.2011.06.007

Cruz, F. C., Javier Rubio, F., and Hope, B. T. (2015). Using c-fos to study neuronal ensembles in corticostriatal circuitry of addiction. Brain Res. 1628, 157-173. doi: 10.1016/j.brainres.2014.11.005

Dalton, V. S., Kolshus, E., and McLoughlin, D. M. (2014). Epigenetics and depression: return of the repressed. J. Affect. Disord. 155, 1-12. doi: 10.1016/j.jad.2013.10.028

Dash, P. K., Hochner, B., and Kandel, E. R. (1990). Injection of the cAMPresponsive element into the nucleus of Aplysia sensory neurons blocks longterm facilitation. Nature 345, 718-721. doi: 10.1038/345718a0

Dobrazanski, P., Noguchi, T., Kovary, K., Rizzo, C. A., Lazo, P. S., and Bravo, R. (1991). Both products of the fosB gene, FosB and its short form, FosB/SF, are transcriptional activators in fibroblasts. Mol. Cell. Biol. 11, 5470-5478. doi: 10.1128/MCB.11.11.5470

Donahue, R. J., Muschamp, J. W., Russo, S. J., Nestler, E. J., and Carlezon, W. A. Jr. (2014). Effects of striatal $\triangle F$ FosB overexpression and ketamine on social defeat stress-induced anhedonia in mice. Biol. Psychiatry 76, 550-558. doi: 10.1016/j.biopsych.2013.12.014

Duman, R. S. (2004). Depression: a case of neuronal life and death? Biol. Psychiatry 56, 140-145. doi: 10.1016/j.biopsych.2004.02.033

Eagle, A. L., Gajewski, P. A., Yang, M., Kechner, M. E., Al Masraf, B. S., Kennedy, P. J., et al. (2015). Experience-dependent induction of hippocampal $\triangle$ FosB controls learning. J. Neurosci. 35, 13773-13783. doi: 10.1523/JNEUROSCI.2083-15.2015

Elizalde, N., Pastor, P. M., Garcia-Garcia, A. L., Serres, F., Venzala, E., Huarte, J., et al. (2010). Regulation of markers of synaptic function in mouse models of depression: chronic mild stress and decreased expression of VGLUT1. J. Neurochem. 114, 1302-1314. doi: 10.1111/j.1471-4159.2010.06854.x

Fanselow, M. S. (2000). Contextual fear, gestalt memories, and the hippocampus. Behav. Brain Res. 110, 73-81. doi: 10.1016/S0166-4328(99)00186-2

Ferrara, P., Andermarcher, E., Bossis, G., Acquaviva, C., Brockly, F., JarielEncontre, I., et al. (2003). The structural determinants responsible for cFos protein proteasomal degradation differ according to the conditions of expression. Oncogene 22, 1461-1474. doi: 10.1038/sj.onc.1206266

Floresco, S. B. (2015). The nucleus accumbens: an interface between cognition, emotion, and action. Annu. Rev. Psychol. 66, 25-52. doi: 10.1146/annurev-psych-010213-115159

Furukawa-Hibi, Y., Nagai, T., Yun, J., and Yamada, K. (2015). Stress increases DNA methylation of the neuronal PAS domain 4 (Npas4) gene. Neuroreport 26, 827-832. doi: 10.1097/WNR.0000000000000430

Furukawa-Hibi, Y., Yun, J., Nagai, T., and Yamada, K. (2012). Transcriptional suppression of the neuronal PAS domain 4 (Npas4) gene by stress via the binding of agonist-bound glucocorticoid receptor to its promoter. J. Neurochem. 123, 866-875. doi: 10.1111/jnc.12034

Gallitano, A. L., Tillman, R., Dinu, V., and Geller, B. (2012). Family-based association study of early growth response gene 3 with child bipolar I disorder. J. Affect. Disord. 138, 387-396. doi: 10.1016/j.jad.2012.01.011

Gallitano-Mendel, A., Wozniak, D. F., Pehek, E. A., and Milbrandt, J. (2008). Mice lacking the immediate early gene Egr3 respond to the antiaggressive effects of clozapine yet are relatively resistant to its sedating effects. Neuropsychopharmacology 33, 1266-1275. doi: 10.1038/sj.npp.13 01505

Geaghan, M., and Cairns, M. J. (2015). MicroRNA and posttranscriptional dysregulation in psychiatry. Biol. Psychiatry 78, 231-239. doi: 10.1016/j.biopsych.2014.12.009

Gruber, A. J., Hussain, R. J., and O'Donnell, P. (2009). The nucleus accumbens: a switchboard for goal-directed behaviors. PLOS ONE 4:e5062. doi: 10.1371/journal.pone.0005062

Grueter, B. A., Robison, A. J., Neve, R. L., Nestler, E. J., and Malenka, R. C. (2013). FosB differentially modulates nucleus accumbens direct and indirect pathway function. Proc. Natl. Acad. Sci. U.S.A. 110, 1923-1928. doi: 10.1073/pnas.1221742110

Guidotti, G., Calabrese, F., Auletta, F., Olivier, J., Racagni, G., Homberg, J., et al. (2012). Developmental influence of the serotonin transporter on the expression of npas4 and GABAergic markers: modulation by antidepressant treatment. Neuropsychopharmacology 37, 746-758. doi: 10.1038/npp.2011.252 
Guo, M. L., Xue, B., Jin, D. Z., Liu, Z. G., Fibuch, E. E., Mao, L. M., et al. (2012). Upregulation of Npas4 protein expression by chronic administration of amphetamine in rat nucleus accumbens in vivo. Neurosci. Lett. 528, 210-214. doi: 10.1016/j.neulet.2012.07.048

Gutièrrez-Mecinas, M., Trollope, A. F., Collins, A., Morfett, H., Hesketh, S. A., Kersante, F., et al. (2011). Long-lasting behavioral responses to stress involve a direct interaction of glucocorticoid receptors with ERK1/2MSK1-Elk-1 signaling. Proc. Natl. Acad. Sci. U.S.A. 108, 13806-13811. doi: $10.1073 /$ pnas. 1104383108

Heiman, M., Kulicke, R., Fenster, R. J., Greengard, P., and Heintz, N. (2014). Cell type-specific mRNA purification by translating ribosome affinity purification (TRAP). Nat. Protoc. 9, 1282-1291. doi: 10.1038/nprot.2014.085

Hope, B. T., Nye, H. E., Kelz, M. B., Self, D. W., Iadarola, M. J., Nakabeppu, Y., et al. (1994). Induction of a long-lasting AP-1 complex composed of altered Fos-like proteins in brain by chronic cocaine and other chronic treatments. Neuron 13, 1235-1244. doi: 10.1016/0896-6273(94)90061-2

Iasevoli, F., Tomasetti, C., Ambesi-Impiombato, A., Muscettola, G., and de Bartolomeis, A. (2009). Dopamine receptor subtypes contribution to Homerla induction: insights into antipsychotic molecular action. Prog. Neuropsychopharmacol. Biol. Psychiatry 33, 813-821. doi: 10.1016/j.pnpbp.2009.02.009

Ibi, D., Takuma, K., Koike, H., Mizoguchi, H., Tsuritani, K., Kuwahara, Y., et al. (2008). Social isolation rearing-induced impairment of the hippocampal neurogenesis is associated with deficits in spatial memory and emotion-related behaviors in juvenile mice. J. Neurochem. 105, 921-932. doi: 10.1111/j.1471-4159.2007.05207.x

Ieraci, A., Mallei, A., and Popoli, M. (2016). Social isolation stress induces anxiousdepressive-like behavior and alterations of neuroplasticity-related genes in adult male mice. Neural Plast. 2016:6212983. doi: 10.1155/2016/6212983

Janak, P. H., and Tye, K. M. (2015). From circuits to behaviour in the amygdala. Nature 517, 284-292. doi: 10.1038/nature14188

Kalivas, P. W., Volkow, N., and Seamans, J. (2005). Unmanageable motivation in addiction: a pathology in prefrontal-accumbens glutamate transmission. Neuron 45, 647-650. doi: 10.1016/j.neuron.2005.02.005

Kandel, E. R. (2012). The molecular biology of memory: cAMP, PKA, CRE, CREB-1, CREB-2, and CPEB. Mol. Brain 5:14. doi: 10.1186/1756-6606-5-14

Kanoski, S. E., and Grill, H. J. (2017). Hippocampus contributions to food intake control: mnemonic, neuroanatomical, and endocrine mechanisms. Biol. Psychiatry 81, 748-756. doi: 10.1016/j.biopsych.2015.09.011

Kida, S., and Serita, T. (2014). Functional roles of CREB as a positive regulator in the formation and enhancement of memory. Brain Res. Bull 105, 17-24. doi: 10.1016/j.brainresbull.2014.04.011

Kim, J. H., Roberts, D. S., Hu, Y., Lau, G. C., Brooks-Kayal, A. R., Farb, D. H., et al. (2012). Brain-derived neurotrophic factor uses CREB and Egr3 to regulate NMDA receptor levels in cortical neurons. J. Neurochem. 120, 210-219. doi: 10.1111/j.1471-4159.2011.07555.x

Knapska, E., and Kaczmarek, L. (2004). A gene for neuronal plasticity in the mammalian brain: Zif268/Egr-1/NGFI-A/Krox-24/TIS8/ZENK? Prog. Neurobiol. 74, 183-211. doi: 10.1016/j.pneurobio.2004.05.007

Knöll, B., and Nordheim, A. (2009). Functional versatility of transcription factors in the nervous system: the SRF paradigm. Trends Neurosci. 32, 432-442. doi: 10.1016/j.tins.2009.05.004

Kovács, K. J. (1998). c-Fos as a transcription factor: a stressful (re)view from a functional map. Neurochem. Int. 33, 287-297. doi: 10.1016/S0197-0186(98)00023-0

Kovács, K. J. (1998). Invited review c-Fos as a transcription factor: a stressful (re)view from a functional map. Neurochem. Int. 33, 287-297. doi: 10.1016/S0197-0186(98)00023-0

Lammel, S., Tye, K. M., and Warden, M. R. (2014). Progress in understanding mood disorders: optogenetic dissection of neural circuits. Genes Brain Behav. 13, 38-51. doi: 10.1111/gbb.12049

Li, L., Carter, J., Gao, X., Whitehead, J., and Tourtellotte, W. G. (2005). The neuroplasticity-associated arc gene is a direct transcriptional target of early growth response (Egr) transcription factors. Mol. Cell Biol. 25, 10286-10300. doi: 10.1128/MCB.25.23.10286-10300.2005

Li, Y., Pehrson, A. L., Waller, J. A., Dale, E., Sanchez, C., and Gulinello, M. (2015). A critical evaluation of the activity-regulated cytoskeleton-associated protein (Arc/Arg3.1)'s putative role in regulating dendritic plasticity, cognitive processes, and mood in animal models of depression. Front. Neurosci. 9:279. doi: 10.3389/fnins.2015.00279

Lin, Y., Bloodgood, B. L., Hauser, J. L., Lapan, A. D., Koon, A. C., Kim, T. K., et al. (2008). Activity-dependent regulation of inhibitory synapse development by Npas4. Nature 455, 1198-1204. doi: 10.1038/nature07319

Lobo, M. K. (2009). Molecular profiling of striatonigral and striatopallidal medium spiny neurons past, present, and future. Int. Rev. Neurobiol. 89, 1-35. doi: 10.1016/S0074-7742(09)89001-6

Lobo, M. K., Zaman, S., Damez-Werno, D. M., Koo, J. W., Bagot, R. C., DiNieri, J. A., et al. (2013). $\Delta$ FosB induction in striatal medium spiny neuron subtypes in response to chronic pharmacological, emotional, and optogenetic stimuli. J. Neurosci. 33, 18381-18395. doi: 10.1523/JNEUROSCI.1875-13.2013

Luking, K. R., Pagliaccio, D., Luby, J. L., and Barch, D. M. (2016). Reward processing and risk for depression across development. Trends Cogn. Sci. 20, 456-468. doi: 10.1016/j.tics.2016.04.002

Maze, I., Covington, H. E. III, Dietz, D. M., LaPlant, Q., Renthal, W., Russo, S. J., et al. (2010). Essential role of the histone methyltransferase G9a in cocaine-induced plasticity. Science 327, 213-216. doi: 10.1126/science.1179438

McCullough, K. M., Morrison, F. G., and Ressler, K. J. (2016). Bridging the gap: towards a cell-type specific understanding of neural circuits underlying fear behaviors. Neurobiol. Learn. Mem. 135, 27-39. doi: 10.1016/j.nlm.2016.07.025

Messaoudi, E., Kanhema, T., Soulé, J., Tiron, A., Dagyte, G., da Silva, B., et al. (2007). Sustained Arc/Arg3.1 synthesis controls longterm potentiation consolidation through regulation of local actin polymerization in the dentate gyrus in vivo. J. Neurosci. 27, 10445-10455. doi: 10.1523/JNEUROSCI.2883-07.2007

Molteni, R., Calabrese, F., Chourbaji, S., Brandwein, C., Racagni, G., Gass, P., et al. (2010). Depression-prone mice with reduced glucocorticoid receptor expression display an altered stress-dependent regulation of brain-derived neurotrophic factor and activity-regulated cytoskeleton-associated protein. J. Psychopharmacol. 24, 595-603. doi: 10.1177/0269881108099815

Muschamp, J. W., Nemeth, C. L., Robison, A. J., Nestler, E. J., and Carlezon, W. A. Jr. (2012). $\triangle$ FosB enhances the rewarding effects of cocaine while reducing the pro-depressive effects of the kappa-opioid receptor agonist U50488. Biol. Psychiatry 71, 44-50. doi: 10.1016/j.biopsych.2011.08.011

Myrum, C., Baumann, A., Bustad, H. J., Flydal, M. I., Mariaule, V., Alvira, S., et al. (2015). Arc is a flexible modular protein capable of reversible self-oligomerization. Biochem. J. 468, 145-158. doi: 10.1042/BJ201 41446

Nestler, E. J. (2015a). Role of the brain's reward circuitry in depression: transcriptional mechanisms. Int. Rev. Neurobiol. 124, 151-170. doi: 10.1016/bs.irn.2015.07.003

Nestler, E. J. (2015b). FosB: a transcriptional regulator of stress and antidepressant responses. Eur. J. Pharmacol. 753, 66-72. doi: 10.1016/j.ejphar.2014.10.034

Nestler, E. J., Hyman, S. E., Holtzman, D. M., and Malenka, R. C. (2015). Molecular Neuropharmacology: A Foundation for Clinical Neuroscience, 3rd Edn. Columbus, OH: McGraw-Hill Education, 528.

Nestler, E. J., Kelz, M. B., and Chen, J. (1999). $\triangle$ FosB: a molecular mediator of long-term neural and behavioral plasticity. Brain Res. 835, 10-17. doi: 10.1016/S0006-8993(98)01191-3

Newton, S. S., Thome, J., Wallace, T. L., Shirayama, Y., Schlesinger, L., Sakai, N., et al. (2002). Inhibition of cAMP response element-binding protein or dynorphin in the nucleus accumbens produces an antidepressant-like effect. J. Neurosci. 22, 10883-10890.

Nibuya, M., Morinobu, S., and Duman, R. S. (1995). Regulation of BDNF and trkB mRNA in rat brain by chronic electroconvulsive seizure and antidepressant drug treatments. J. Neurosci. 15, 7539-7547.

Nibuya, M., Nestler, E. J., and Duman, R. S. (1996). Chronic antidepressant administration increases the expression of cAMP response element binding protein (CREB) in rat hippocampus. J. Neurosci. 16, 2365-2372.

Peebles, C. L., Yoo, J., Thwin, M. T., Palop, J. J., Noebels, J. L., and Finkbeiner, S. (2010). Arc regulates spine morphology and maintains network stability in vivo. Proc. Natl. Acad. Sci. U.S.A. 107, 18173-18178. doi: 10.1073/pnas. 10065 46107

Perrotti, L. I., Hadeishi, Y., Ulery, P. G., Barrot, M., Monteggia, L., Duman, R. S., et al. (2004). Induction of $\triangle F o s B$ in reward-related brain structures after chronic stress. J. Neurosci. 24, 10594-10602. doi: 10.1523/JNEUROSCI.2542-04.2004 
Petersohn, D., and Thiel, G. (1996). Role of zinc-finger proteins Sp1 and zif268/egr1 in transcriptional regulation of the human synaptobrevin II gene. Eur. J. Biochem. 239, 827-834. doi: 10.1111/j.1432-1033.1996.0827u.x

Pfaffenseller, B., da Silva Magalhaes, P. V., De Bastiani, M. A., Castro, M. A., Gallitano, A. L., Kapczinski, F., et al. (2016). Differential expression of transcriptional regulatory units in the prefrontal cortex of patients with bipolar disorder: potential role of early growth response gene 3. Transl. Psychiatry 6, e805. doi: 10.1038/tp.2016.78

Pliakas, A. M., Carlson, R. R., Neve, R. L., Konradi, C., Nestler, E. J., and Carlezon, W. A. Jr. (2001). Altered responsiveness to cocaine and increased immobility in the forced swim test associated with elevated cAMP response element-binding protein expression in nucleus accumbens. J. Neurosci. 21, 7397-7403.

Ploski, J. E., Monsey, M. S., Nguyen, T., DiLeone, R. J., and Schafe, G. E. (2011). The neuronal pas domain protein 4 (Npas4) is required for new and reactivated fear memories. PLoS ONE 6:e23760. doi: 10.1371/journal.pone.0023760

Ramamoorthi, K., Fropf, R., Belfort, G. M., Fitzmaurice, H. L., McKinney, R. M., Neve, R. L., et al. (2011). Npas4 regulates a transcriptional program in CA3 required for contextual memory formation. Science 334, 1669-1675. doi: $10.1126 /$ science. 1208049

Ramanan, N., Shen, Y., Sarsfield, S., Lemberger, T., Schutz, G., Linden, D. J., et al. (2005). SRF mediates activity-induced gene expression and synaptic plasticity but not neuronal viability. Nat. Neurosci. 8, 759-767. doi: 10.1038/nn1462

Reul, J. M. (2014). Making memories of stressful events: a journey along epigenetic, gene transcription, and signaling pathways. Front. Psychiatry 5:5. doi: 10.3389/fpsyt.2014.00005

Rietschel, M., Mattheisen, M., Frank, J., Treutlein, J., Degenhardt, F., Breuer, R., et al. (2010). Genome-wide association-, replication-, and neuroimaging study implicates HOMER1 in the etiology of major depression. Biol. Psychiatry 68, 578-585. doi: 10.1016/j.biopsych.2010.05.038

Roberts, D. S., Raol, Y. H., Bandyopadhyay, S., Lund, I. V., Budreck, E. C., Passini, M. A., et al. (2005). Egr3 stimulation of GABRA4 promoter activity as a mechanism for seizure-induced up-regulation of $\mathrm{GABA}(\mathrm{A})$ receptor alpha4 subunit expression. Proc. Natl. Acad. Sci. U.S.A. 102, 11894-11899. doi: 10.1073/pnas.0501434102

Robinson, T. E., and Kolb, B. (1999). Alterations in the morphology of dendrites and dendritic spines in the nucleus accumbens and prefrontal cortex following repeated treatment with amphetamine or cocaine. Eur. J. Neurosci. 11, 1598-1604. doi: 10.1046/j.1460-9568.1999.00576.x

Robison, A. J., Vialou, V., Sun, H.-S., Labonte, B., Golden, S. A., Dias, C., et al. (2014). Fluoxetine epigenetically Alters the CaMKII $\alpha$ promoter in nucleus accumbens to regulate $\Delta$ FosB binding and antidepressant effects. Neuropsychopharmacology 39, 1178-1186. doi: 10.1038/npp.2013.319

Russo, S. J., and Nestler, E. J. (2013). The brain reward circuitry in mood disorders. Nat. Rev. Neurosci. 14, 609-625. doi: 10.1038/nrn3381

Russo, S. J., Dietz, D. M., Dumitriu, D., Morrison, J. H., Malenka, R. C., and Nestler, E. J. (2010). The addicted synapse: mechanisms of synaptic and structural plasticity in nucleus accumbens. Trends Neurosci. 33, 267-276. doi: 10.1016/j.tins.2010.02.002

Sakurai, K., Zhao, S., Takatoh, J., Rodriguez, E., Lu, J., Leavitt, A. D., et al. (2016). Capturing and manipulating activated neuronal ensembles with CANE delineates a hypothalamic social-fear circuit. Neuron 92, 739-753. doi: 10.1016/j.neuron.2016.10.015

Sala, C., Futai, K., Yamamoto, K., Worley, P. F., Hayashi, Y., and Sheng, M. (2003). Inhibition of dendritic spine morphogenesis and synaptic transmission by activity-inducible protein Homer1a. J. Neurosci. 23, 6327-6337.

Saunderson, E. A., Spiers, H., Mifsud, K. R., Gutierrez-Mecinas, M., Trollope, A. F., Shaikh, A., et al. (2016). Stress-induced gene expression and behavior are controlled by DNA methylation and methyl donor availability in the dentate gyrus. Proc. Natl. Acad. Sci. U.S.A. 113, 4830-4835. doi: $10.1073 /$ pnas. 1524857113

Sesack, S. R., and Grace, A. A. (2010). Cortico-basal ganglia reward network: microcircuitry. Neuropsychopharmacology 35, 27-47. doi: 10.1038/npp.2009.93

Sheng, M., and Greenberg, M. E. (1990). The regulation and function of c-fos and other immediate early genes in the nervous system. Neuron 4, 477-485. doi: 10.1016/0896-6273(90)90106-P

Sim, S. Y., Antolin, S., Lin, C. W., Lin, Y. X., and Lois, C. (2013). Increased cell-intrinsic excitability induces synaptic changes in new neurons in the adult dentate gyrus that require Npas4. J. Neurosci. 33, 7928-7940. doi: 10.1523/JNEUROSCI.1571-12.2013

Spiegel, I., Mardinly, A. R., Gabel, H. W., Bazinet, J. E., Couch, C. H., Tzeng, C. P., et al. (2014). Npas4 regulates excitatory-inhibitory balance within neural circuits through cell-type-specific gene programs. Cell 157, 1216-1229. doi: 10.1016/j.cell.2014.03.058

Stuber, G. D., Sparta, D. R., Stamatakis, A. M., van Leeuwen, W. A., Hardjoprajitno, J. E., Cho, S., et al. (2011). Excitatory transmission from the amygdala to nucleus accumbens facilitates reward seeking. Nature 475, 377-380. doi: 10.1038/nature10194

Sun, P., Wang, F., Wang, L., Zhang, Y., Yamamoto, R., Sugai, T., et al. (2011). Increase in cortical pyramidal cell excitability accompanies depression-like behavior in mice: a transcranial magnetic stimulation study. J. Neurosci. 31, 16464-16472. doi: 10.1523/JNEUROSCI.154211.2011

Surmeier, D. J., Ding, J., Day, M., Wang, Z., and Shen, W. (2007). D1 and D2 dopamine-receptor modulation of striatal glutamatergic signaling in striatal medium spiny neurons. Trends Neurosci. 30, 228-235. doi: 10.1016/j.tins.2007.03.008

Thome, J., Sakai, N., Shin, K., Steffen, C., Zhang, Y. J., Impey, S., et al. (2000). cAMP response element-mediated gene transcription is upregulated by chronic antidepressant treatment. J. Neurosci. 20, 4030-4036.

Tu, J. C., Xiao, B., Yuan, J. P., Lanahan, A. A., Leoffert, K., Li, M., et al. (1998). Homer binds a novel proline-rich motif and links group 1 metabotropic glutamate receptors with IP3 receptors. Neuron 21, 717-726. doi: 10.1016/S0896-6273(00)80589-9

Ulery, P. G., Rudenko, G., and Nestler, E. J. (2006). Regulation of $\triangle$ FosB stability by phosphorylation. J. Neurosci. 26, 5131-5142. doi: 10.1523/JNEUROSCI.4970-05.2006

Ulery-Reynolds, P. G., Castillo, M. A., Vialou, V., Russo, S. J., and Nestler, E. J. (2009). Phosphorylation of $\triangle$ FosB mediates its stability in vivo. Neuroscience 158, 369-372. doi: 10.1016/j.neuroscience.2008.10.059

Vezina, P., Giovino, A. A., Wise, R. A., and Stewart, J. (1989). Environmentspecific cross-sensitization between the locomotor activating effects of morphine and amphetamine. Pharmacol. Biochem. Behav. 32, 581-584. doi: 10.1016/0091-3057(89)90201-3

Vialou, V., Bagot, R. C., Cahill, M. E., Ferguson, D., Robison, A. J., Dietz, D. M., et al. (2014). Prefrontal cortical circuit for depression- and anxietyrelated behaviors mediated by cholecystokinin: role of $\Delta$ FosB. J. Neurosci. 34, 3878-3887. doi: 10.1523/JNEUROSCI.1787-13.2014

Vialou, V., Feng, J., Robison, A. J., Ku, S. M., Ferguson, D., Scobie, K. N., et al. (2012). Serum response factor and cAMP response element binding protein are both required for cocaine induction of $\Delta$ FosB. J. Neurosci. 32, 7577-7584. doi: 10.1523/JNEUROSCI.1381-12.2012

Vialou, V., Maze, I., Renthal, W., LaPlant, Q. C., Watts, E. L., Mouzon, E., et al. (2010b). Serum response factor promotes resilience to chronic social stress through the induction of $\Delta$ FosB. J. Neurosci. 30, 14585-14592. doi: 10.1523/JNEUROSCI.2496-10.2010

Vialou, V., Robison, A. J., Laplant, Q. C., Covington, H. E. III, Dietz, D. M., Ohnishi, Y. N., et al. (2010a). $\triangle$ FosB in brain reward circuits mediates resilience to stress and antidepressant responses. Nat. Neurosci. 13, 745-752. doi: $10.1038 / \mathrm{nn} .2551$

Vialou, V., Thibault, M., Kaska, S., Cooper, S., Gajewski, P., Eagle, A., et al. (2015). Differential induction of FosB isoforms throughout the brain by fluoxetine and chronic stress. Neuropharmacology 99, 28-37. doi: 10.1016/j.neuropharm.2015.07.005

Wagner, K. V., Hartmann, J., Labermaier, C., Hausl, A. S., Zhao, G., Harbich, D., et al. (2015). Homer $1 /$ mGluR5 activity moderates vulnerability to chronic social stress. Neuropsychopharmacology 40, 1222-1233. doi: $10.1038 /$ npp. 2014.308

Wallace, D. L., Han, M. H., Graham, D. L., Green, T. A., Vialou, V., Iniguez, S. D., et al. (2009). CREB regulation of nucleus accumbens excitability mediates social isolation-induced behavioral deficits. Nat. Neurosci. 12, 200-209. doi: $10.1038 / \mathrm{nn} .2257$

West, A. E., and Greenberg, M. E. (2011). Neuronal activity-regulated gene transcription in synapse development and cognitive function. Cold Spring Harb. Perspect. Biol. 3:a005744. doi: 10.1101/cshperspect.a005744 
Williams, A. A., Ingram, W. M., Levine, S., Resnik, J., Kamel, C. M., Lish, J. R., et al. (2012). Reduced levels of serotonin 2A receptors underlie resistance of Egr3-deficient mice to locomotor suppression by clozapine. Neuropsychopharmacology 37, 2285-2298. doi: 10.1038/npp. 2012.81

Yin, J. C., Wallach, J. S., Del Vecchio, M., Wilder, E. L., Zhou, H., Quinn, W. G., et al. (1994). Induction of a dominant negative CREB transgene specifically blocks long-term memory in Drosophila. Cell 79, 49-58. doi: 10.1016/0092-8674(94)90399-9

Yun, J., Koike, H., Ibi, D., Toth, E., Mizoguchi, H., Nitta, A., et al. (2010). Chronic restraint stress impairs neurogenesis and hippocampus-dependent fear memory in mice: possible involvement of a brain-specific transcription factor Npas4. J. Neurochem. 114, 1840-1851. doi: 10.1111/j.1471-4159.2010. 06893.x
Zhang, W., Wu, J., Ward, M. D., Yang, S., Chuang, Y. A., Xiao, M., et al. (2015) Structural basis of arc binding to synaptic proteins: implications for cognitive disease. Neuron 86, 490-500. doi: 10.1016/j.neuron.2015.03.030

Conflict of Interest Statement: The authors declare that the research was conducted in the absence of any commercial or financial relationships that could be construed as a potential conflict of interest.

Copyright $\odot 2017$ Manning, Williams and Robison. This is an open-access article distributed under the terms of the Creative Commons Attribution License (CC BY). The use, distribution or reproduction in other forums is permitted, provided the original author(s) or licensor are credited and that the original publication in this journal is cited, in accordance with accepted academic practice. No use, distribution or reproduction is permitted which does not comply with these terms. 